\title{
Investigation of Non-Uniform Rust Distribution and Its Effects on Corrosion Induced Cracking in Reinforced Concrete
}

\author{
Wahyuniarsih Sutrisno ${ }^{1, *}$, Priyo Suprobo ${ }^{1}$, Endah Wahyuni $^{1}$, Data Iranata $^{1}$ \\ ${ }^{1}$ Department of Civil Engineering of Institut Teknologi Sepuluh Nopember, ITS Sukolilo Campus \\ Surabaya Indonesia
}

\begin{abstract}
Uniform corrosion still widely used by a lot of researchers and engineers to analyze the corrosion induced cracking. However, in practice, corrosion process occurred non-uniformly. The part nearest to the exposed surface is more likely to have faster corrosion initiation compared with other regions. This research is mainly focused on investigating the effect of non-uniform rust distribution to cover cracking in reinforced concrete. An experimental test performed using accelerated corrosion test by using 5\% $\mathrm{NaCl}$ solution and applied a constant electric current to the concrete samples. The rust distribution and measurement were observed by using a digital microscope. Based on the experimental result, it was found that the rust was distributed in a non-uniform pattern. As a result, the cracks also formed non-uniformly along the perimeter of steel bar. At the last part of this paper, a simulation result of concrete cracking induced by non-uniform corrosion is presented. The result compared with a simulation using uniform corrosion assumption to investigate the damage pattern of each model. The simulation result reveals stress evolution due to rust expansion which leads to concrete cracking. Furthermore, a comparison of stresses induced by non-uniform corrosion and uniform corrosion indicates that non-uniform corrosion could lead to earlier damage to the structure which is specified by the formation and propagation of the crack.
\end{abstract}

\section{Introduction}

Reinforcement corrosion induced by chloride ingress is a major durability problem in reinforced concrete structure. Furthermore, this condition can affect the serviceability and finally leads to damage of the structure. The corrosion process starts with depassivation. Depassivation is a condition when a passive layer of the steel is damage. This process followed with the formation of the rust at the interface between steel bar and concrete. The volume of rust will continue to increase as corrosion processes happen continuously. The volume of the rust can exceed 2-6 times the volume of the original steel, and it can generate outward expansive pressure which causes cracks in the concrete. The overall illustration regarding this process shown in Fig. 1.

\footnotetext{
*Corresponding author: niar1206@gmail.com
} 

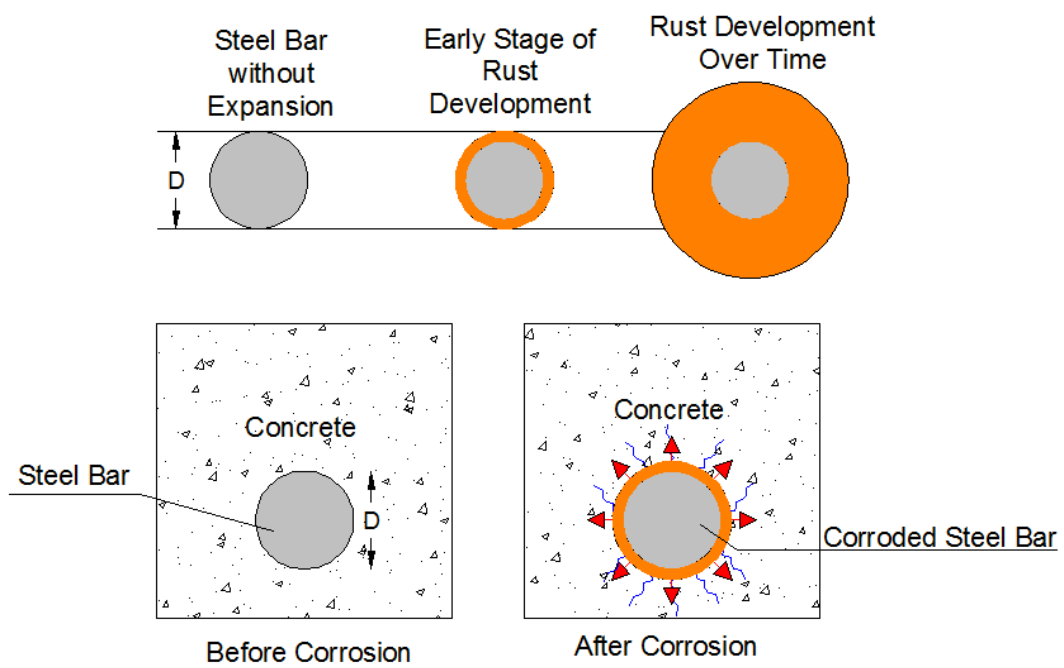

Fig. 1. Illustration of Corroded Steel Bar Induced Concrete Cracking in Reinforced Concrete

Crack on a structural element is undesirable because it can damage the structure by reducing the strength of the structure and increasing concrete permeability. It is also aggravating the bonding between steel and concrete. As the result of concrete cracking development, it can reach the concrete cover and cause failure to the structures. Even though any use of concrete as structural materials will cause a crack, but the crack is still acceptable as long as the width is still within the limits which are not harmful to the user. However, in several conditions, the crack can propagate continuously especially due to environmental influences such as corrosion which can endanger the users of the structure. Therefore, it is imperative to know the damage process of concrete induced by reinforcement corrosion to calculate and predicting the serviceability of the structures.

The total service life of reinforced concrete elements exposed to corrosion is commonly characterized as a two-stage process consisting of an initiation and a propagation period. The crack initiation process is defined as the time taken from corrosion starts until the rust cause crack on the concrete. Furthermore, the propagation period is defined as the time required for a crack to reach specified serviceability or ultimate limit states. Service life has conventionally been taken as equal to the duration of the initiation period, and subsequently, much of the research work has been focused on this area. However, this may be viewed as a conservative failure criterion because the end of the initiation phase only indicates the onset of corrosion and the structure is yet to suffer any effects that may obstruct its functional performance.

Several research have been performed to investigate the corrosion in reinforced concrete and its effects on concrete. Their studies include experimental, analytical and numerical analysis. The numerical and analytical models mainly focused on the development of a predictive model of corrosion induced cracking. The numerical and analytical model consider the realistic failure criteria of the concrete to indicate their structural service life. The end of concrete service life could be shown by depth cracking, cover spalling, and eventually structural collapse. The model usually assumed that the corrosion occurs uniformly around the circumference of the steel bar (Li, Lawanwisut, Zheng, \& Kijawatworawet, 2005; Liu \& Weyers, 1998). However, this condition did not represent the practical situation. On the real condition, the steel corrosion takes place at locations nearest to the exposed surface of the concrete structure. This situation leads to non-uniform rust 
distribution which can generate non-uniform expansive pressure and eventually leads to crack to the structures.

This paper provides an experimental investigation of rust distribution in reinforced concrete due to corrosion. The effect of rust distribution to the concrete cracking also discussed in this article. At the end section of this article, numerical simulation of uniform and non-uniform corrosion induced cracking is presented to get realistic comparison related to damage process of the concrete due to corrosion.

\section{Corrosion Induced Cracking Process in Reinforced Concrete}

It is critical to consider the cracking behavior of concrete cover for the assessment of the remaining strength and service life of concrete structures. Corrosion in reinforced concrete structure due to chloride ingress has a significant contribution to concrete cracking. Corrosion decreases the strength of the concrete by deteriorating the bonding between concrete and steel reinforcement. As a result, the ability of the reinforcement to provide tensile strength and ductility to the concrete decreased [1]. On the steel surfaces, there is a thin passive layer which is used to protect the steel from corrosion. However, when the harmful agent, such as chloride, present in the concrete, the passive layers of the steel can disappear and cause corrosion.

After the depassivation occurs, corrosion of the steel reinforcement is initiated by the reaction between the steel bar with oxygen and water. At the anode reaction, the discrete ions formed and it can react to an insoluble corrosion product. Corrosion reaction of metal are generally written with a simple reaction [2]

$$
\mathrm{M} \rightarrow \mathrm{M}^{2+}+2 \mathrm{e}^{-}
$$

The passive layer of the steel will be lost will act as an anode in reaction process of corrosion. The anode reaction equation can be written as follows:

$$
\mathrm{Fe} \rightarrow \mathrm{Fe}^{2+}+2 \mathrm{e}^{-}
$$

Sudjono [3] explained that the electrons released from the anode reaction cause the oxygen and water, which is located on the surface of the steel, react. The part of this steel becomes the cathode of reinforcing steel corrosion reaction, and the reaction process can be written as follows:

$$
\mathrm{O}^{2}+2 \mathrm{H}_{2} \mathrm{O}+2 \mathrm{e}^{-} \rightarrow 4 \mathrm{OH}^{-}
$$

Both anode and cathode ions react and generate the corrosion product as the following reaction

$$
\begin{gathered}
2 \mathrm{Fe}+\mathrm{O}_{2}+2 \mathrm{H}_{2} \mathrm{O} \rightarrow 2 \mathrm{Fe}^{2+}+4 \mathrm{OH}^{-} \\
2 \mathrm{Fe}^{2+}+4 \mathrm{OH}^{-} \rightarrow 2 \mathrm{Fe}(\mathrm{OH})_{2}
\end{gathered}
$$

As the result of the reaction, $\mathrm{Fe}(\mathrm{OH})_{2}$ will be formed as the original form of the corrosion product. Corrosion is a process which will continue if the concentrations of $\mathrm{O}_{2}$ and $\mathrm{H}_{2} \mathrm{O}$ are sufficient in the concrete. However, this corrosion process can take place more quickly when there are catalysts that can speed up the process of formation of the rust like the presence of chloride ions $\left(\mathrm{Cl}^{-}\right)$. The $\mathrm{Cl}^{-}$ions derived from an aggressive environment such as the environment close to the sea water. Chloride essentially has no effect on the 
formation of rust, but this ion help to destruct the passive layer and accelerate the anode process which resulting speed up the corrosion process. The illustration of corrosion process is shown in Fig 2.

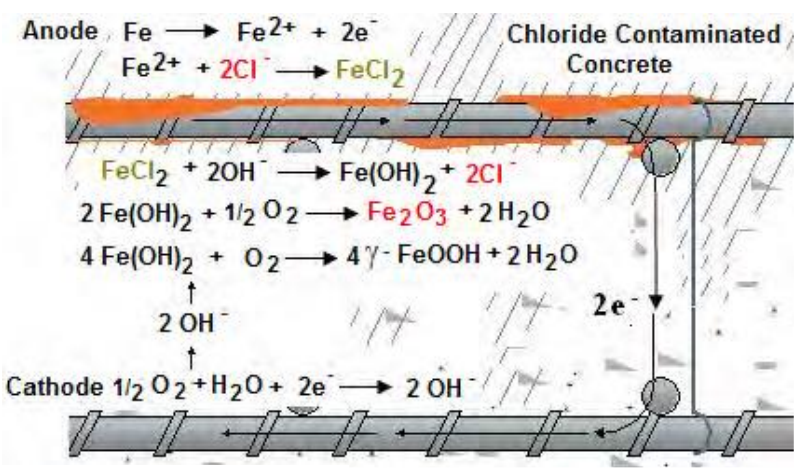

Fig. 2. Chloride Induced Corrosion Process [4]

In general, the occurrence of cracking in concrete due to corrosion on the surface of the concrete and steel covers three stages, which are initiation, expansion and crack stage (Liu and Weeyrs, 1998 in [5]). After the corrosion initiation process, which has been explained previously, the rust start to develop. The development of rust volume can reach two until six times of original steel bar volume. This condition makes the expansive pressure start to present and at one point cause crack on the concrete.

Analysis of cracks which occur in reinforced concrete due to corrosion during this still using the assumption that the corrosion products formed evenly along the perimeter of the reinforcement [2], [6]-[10]. Uniform corrosion assumption illustrate the corrosion products, also known as rust, to be a thick wall which formed around the perimeter of reinforcement and will provide uniform pressure on the expansive concrete.

However, in subsequent studies, it was found that the development of corrosion products (rust) is formed non-uniformly along the perimeter of steel reinforcement [11][14]. Research conducted by [12] stated that there the rust was accumulated at the certain parts around the perimeter of the reinforcement, particularly in part nearest to the exposed surface of the concrete which dealing with the outside environment. In this particular area, the aggressive ions such as chloride ions have more quick infiltration process to the concrete which can accelerate the corrosion process.

Crack analysis using the non-uniform distribution of the rust will provide more accurate analysis because by using this assumption, a greater concentrated expansive pressure will be generated on the cover. This condition will lead to an increase in the speed of crack propagation towards the concrete cover so that the analysis results can be obtained more precise and closer to the actual incident.

\section{Experimental Setup}

The summary of the experimental set up is provided in this section. The sample used in this paper is a concrete cube with dimension $150 \times 150 \times 150 \mathrm{~mm}$ with single reinforcement as shown in Fig. 3. The concrete material used in this experiment is normal concrete with water per cement ratio (w/c) 0.5 . Several days before mixing, the coarse and fine aggregate was washed to remove any fine dust which may increase the water demand, and lower the bond strength. The wet aggregate was then placed in a sealed bucket for one day was allowed for absorption. This treatment can stabilize the moisture content of the aggregate and drain the excess water. After one day the aggregate was dried to reach SSD condition. 
Prior to mixing, the materials were weighed and batched into sealed buckets at least one day in advance.

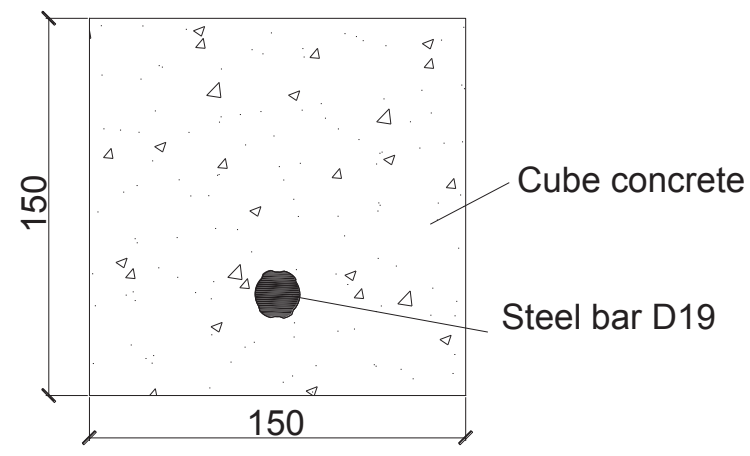

Fig. 3. Cross Section of the Model

The concrete was mixed by a mixer machine, and the special mold was prepared to allow the steel reinforcement embedded in the concrete. The concrete was embedded with single steel reinforcement with diameter $19 \mathrm{~mm}$. The reinforcement was embedded $40 \mathrm{~mm}$ from the exposed surface. The concrete was demolded after 24 hours, and it was cured under wet burlap and plastic in the concrete lab environment. After 28 days, the accelerated corrosion test was performed.

The accelerated corrosion test was carried out to investigate the corrosion induced cracking process in reinforced concrete structures. The corrosion process, rust development, crack initiation and propagation were observed using daily visual observation. The accelerated corrosion process was achieved by applying a constant electrical current to the steel reinforcement by a power supply via a current regulator. The current regulator was used in this experiment to maintain constant current over the time. To generate cracks due to corrosion the accelerated corrosion test used approximately $200 \mu \mathrm{A} / \mathrm{cm}^{2}$ of electric current. The concrete specimen placed in the $5 \% \mathrm{NaCl}$ solution. The accelerated corrosion set up is shown in Fig. 4. The steel bar acts as an anode, and the stainless steel plate which submerged in the $\mathrm{NaCl}$ solution acts as the cathode. The pore fluid in the concrete is the electrolyte of the reaction. All of the samples were cut into four identical pieces to observed the rust distribution and crack propagation.

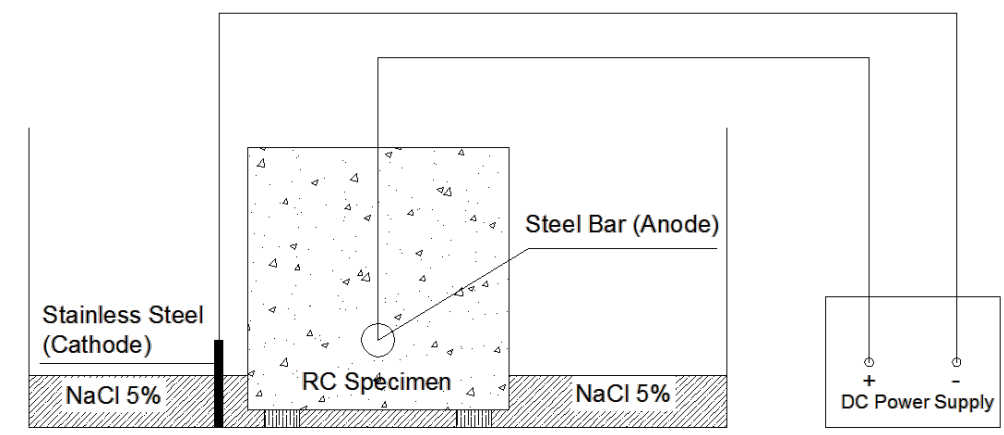

Fig. 4. Accelerated Corrosion Test Set Up 


\section{RESULT AND DISCUSSION}

An accelerated corrosion test was performed to investigate the corrosion induced cracking process in reinforced concrete structures. The first corrosion and crack initiation at the concrete surface were observed using daily visual observation. The process of corrosion initiation is indicated by discoloration of the steel reinforcement. This process happens just 5 hours after the accelerated corrosion test started. As time passed, the corrosion starts to developed and cause bleeding of the rust. This condition indicated by discoloration of the $\mathrm{NaCl}$ solution as shown in Fig. 5.

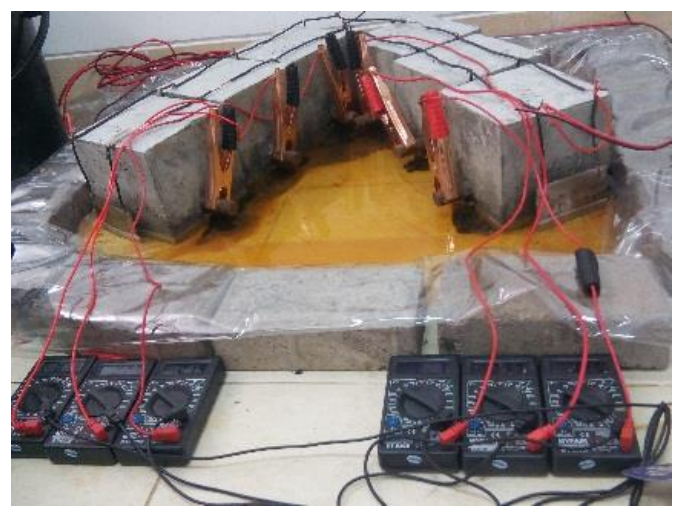

Fig. 5. Discoloration process of $\mathrm{NaCl}$ Solution due to Rust Bleeding

The samples were carefully sliced with a concrete cutter into four identical pieces to have a more detailed observation. Each section was then cut sequentially in the cross sectional direction. The rust distribution observed using photographic analysis to get accurate data regarding the thickness of the rust.

As stated at the beginning of this paper, the primary purposed of this paper is to investigate the rust distribution on the circumference of the steel bar and its effect to cracking. Therefore, the thickness of the rust was observed daily and plotted into several graphs as shown in Fig. 6. The perimeter of steel bar is divided into several polar coordinate, and the thickness is measured according to the polar coordinate. The nonuniform thickness indicates as symbol $\mathrm{Nr}$ on the graph and the polar coordinate $(\theta)$ is measured in degree. The closest part of the exposed surface is assume located at $180^{\circ}$ and the furthest part located at $0^{\circ} / 360^{\circ}$.
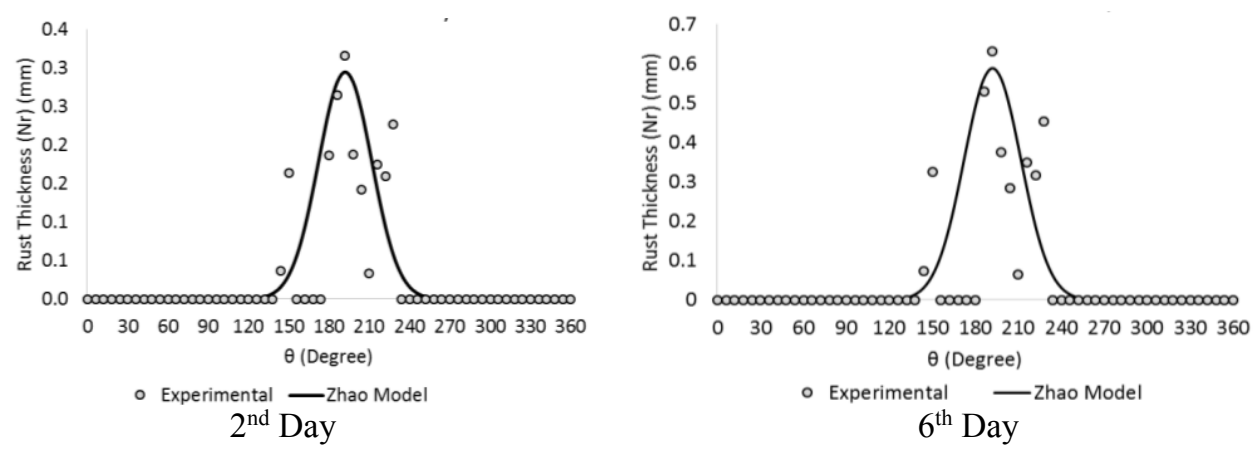

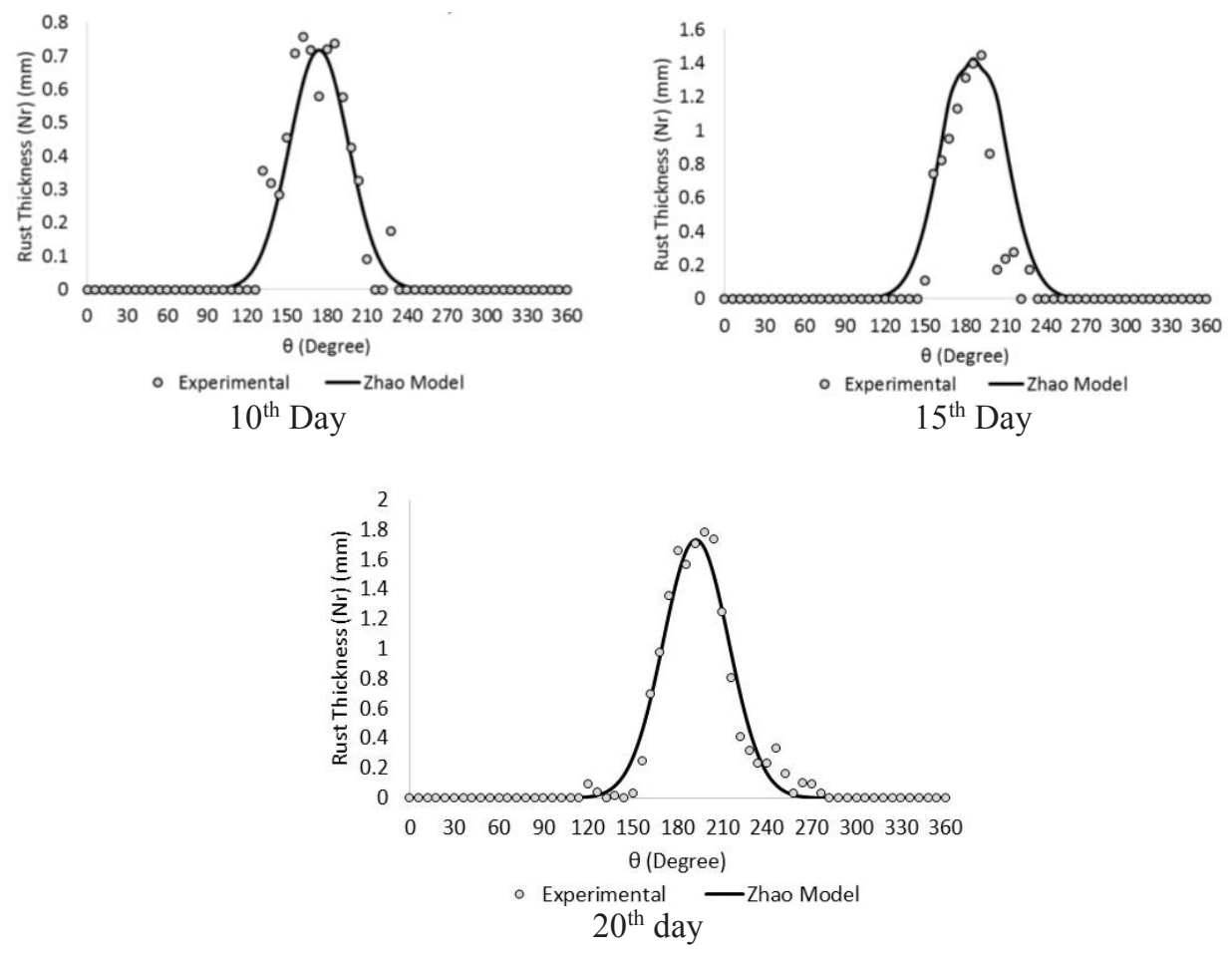

Fig. 6. Rust Distribution Graph from Experimental Result and Its Gaussian Description

In addition to the experimental result, the Gaussian description proposed by Zhao also presented on the Fig. 6. By using the Gaussian function, the non-uniform rust distribution can be idealized. Based on Fig. 6, it can be seen that the thickness of the rust layer is increase as an increase of time. This condition happened because the corrosion process is developed continuously over the time. It is also very clear that the rust distributed nonuniformly along the perimeter of the steel bar. Furthermore, the peak of the curve occurs at the area closest to the exposed surface as expected. This result shows that the area which has the closest distance to the exposed surface is more vulnerable to corrosion because the chloride from outside has faster infiltration to this location than other location.

The curve also showed that the peak of the rust thickness does not always occur at the $180^{\circ}$. The peak of the rust sometimes occurs at $150^{\circ}$ or $210^{\circ}$. The reason behind this phenomena is the use of deformed reinforcement. The geometry of the reinforcement affects the distribution of the rust because it has whorl shape which makes it located closer to the exposed surface than the plain part.

The non-uniform rust distribution apparently affects the cracking propagation on the concrete. Due to non-uniform thickness of rust, the non-uniform expansive pressure is generated and crack start to initiate. The cracking development due to non-uniform corrosion is shown in Fig. 7. 


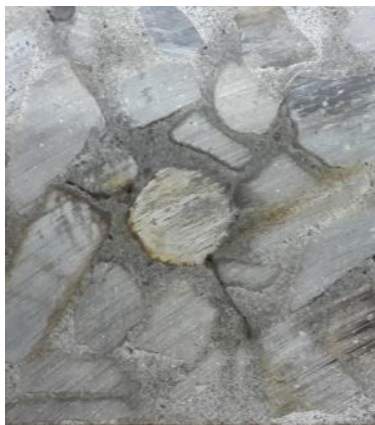

Day $4^{\text {th }}$

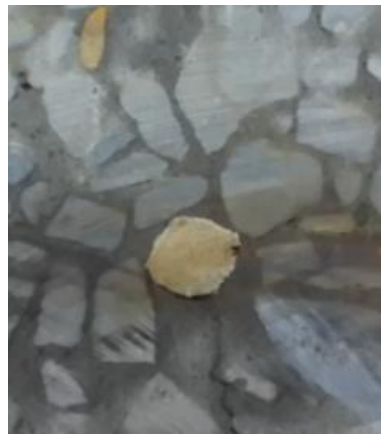

Day $6^{\text {th }}$

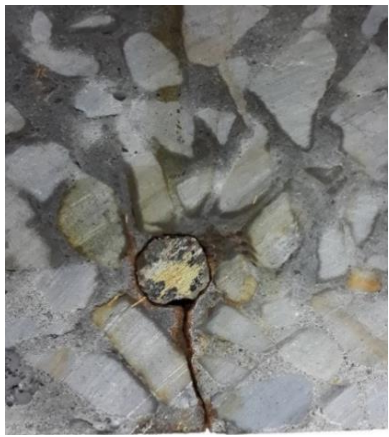

Day $20^{\text {th }}$

Fig. 7. Crack propagation due to Non-Uniform Corrosion

The non-uniform crack propagation, as shown in Fig. 7, is developed as the effect of non-uniform rust distribution. The crack development shows that even though there are several cracks is formed in the bottom part of the concrete-steel bar interface, but only single crack manage to propagate into the concrete cover. After the crack occurs, the rust infiltrates into the crack tip as shown in Fig. 8.

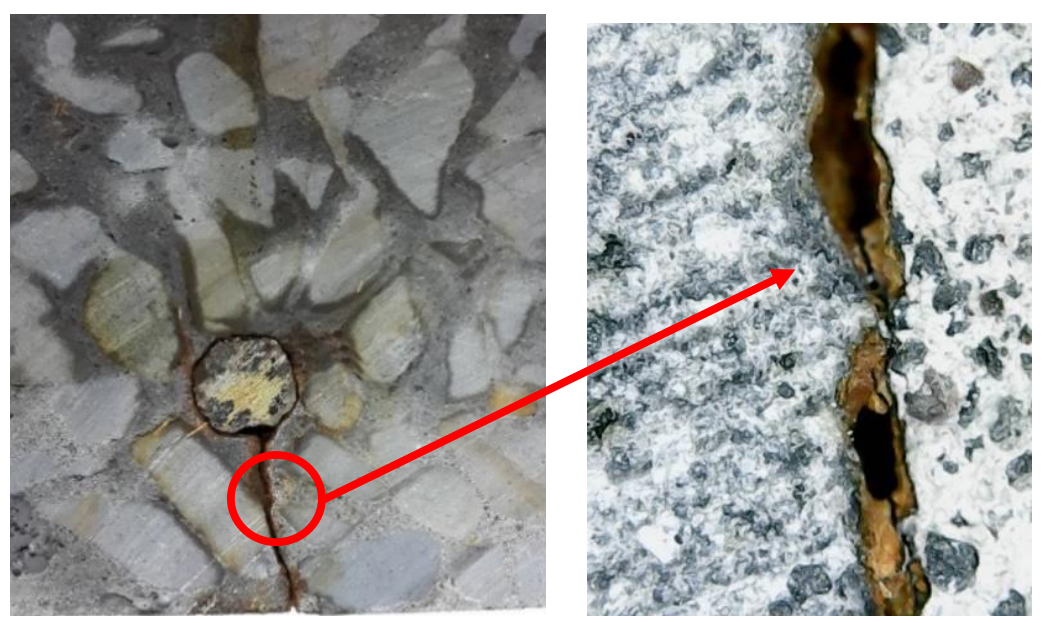

Fig. 8. Rust Distribution at the crack Tip

A finite element simulation is developed to compare the cracking pattern of due to uniform and non-uniform rust distribution. The simulation preformed using the concrete smeared cracking method. The material properties used in this model divided into two categories, elastic and smeared cracking properties. In smeared cracking approach there were three main parameters used to run the analysis such as tension stiffening, failure ratio, and shear retention factor.

The expansive pressure due to uniform and non-uniform corrosion was calculated using the equation proposed by Liu and Weyers [15]. Furthermore, for the non-uniform corrosion, the expansive pressure was calculated by combining the Gaussian model by Zhao and thick walled cylinder based equation by Liu and Wayers [14], [15]. In Liu and Wayers equation, the expansive pressure is affected by the thickness of the corrosion layer. 
When non-uniform corrosion assumption is used, the thickness of corrosion layer was substituted by non-uniform thickness from the Gaussian function.

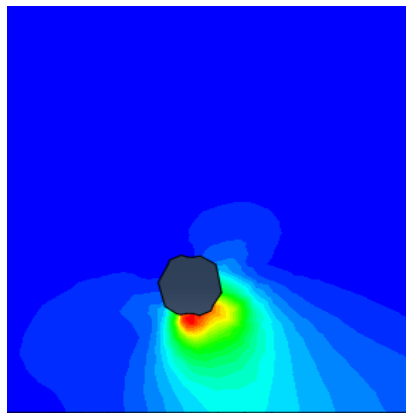

(a)

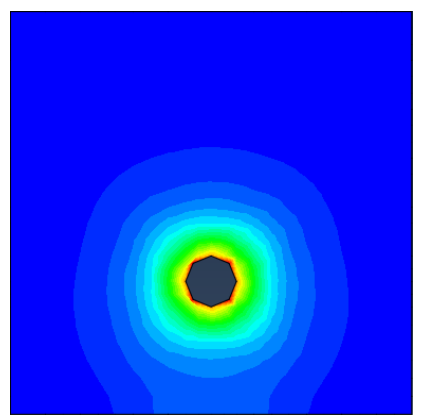

(b)

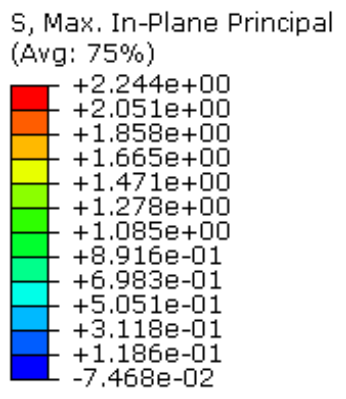

$-7.468 \mathrm{e}-02$

Fig. 9. Finite Element Modeling Result using (a) Non-Uniform and (b) Uniform Rust Distribution Assumption

The Fig. 9 shows stress distribution in the concrete due to expansive internal pressure which reflecting the distribution of the rust. The stress distribution describes the direction of crack propagation in the concrete. Fig. 9a shows that model with non-uniform expansive pressure will lead to a crack which not formed uniformly along the perimeter of the steel bar. This result is contrary to Fig. $9 \mathrm{~b}$ which indicating crack will form uniformly along the perimeter of the steel bar with uniform expansive pressure. Fig. 9 also illustrate that the stress of the model with non-uniform internal expansive pressure is concentrated in one particular area which indicates the possibility of crack propagation. This result is in good agreement with the experimental result as shown in Fig. 8.

\section{CONCLUSION}

A series of the experimental test has been performed to investigate the cracking propagation in the concrete due to corrosion. The experimental test it clearly shows that the rust is formed non-uniformly along the perimeter of the steel bar. Even there were several cracks formed in the concrete along the perimeter of the steel bar, there is only one main crack manage to propagate to the exposed surface. The numerical simulation also performed in this paper, and it shows high agreement with the experimental result. The numerical model shows the differences between using uniform and non-uniform rust distribution assumption. The uniform rust assumption produced uniform expansive pressure and stress distribution along the perimeter of the steel bar as expected. However, non-uniform assumption shows that the stress is concentrated in one particular area. This condition could be taken as a representation of cracking propagation direction in the concrete. The non-uniform corrosion assumption can lead concrete to crack faster in the section closer to the exposed surface and vice versa.

\section{ACKNOWLEDGEMENT}

All of the authors acknowledge the financial support from Directorate General of Higher Education (DIKTI), Ministry of Education and Culture, Republic of Indonesia. 


\section{References}

[1] C. Fang, K. Lundgren, L. Chen, And C. Zhu, "Corrosion Influence On Bond In Reinforced Concrete," Cem. Concr. Res., Vol. 34, No. 11, Pp. 2159-2167, Nov. (2004).

[2] Y. Liu, "Modeling The Time-To-Corrosion Cracking Of The Cover Concrete In Chloride Contaminated Reinforced Concrete Structures," Virginia Polytechnic Institute And State University, (1996).

[3] A. S. Sudjono, "Prediksi Waktu Layan Bangunan Beton Terhadap," Civ. Eng. Dimens., Vol. 7, No. 1, Pp. 6-15, (2007).

[4] X. Shi, N. Xie, K. Fortune, And J. Gong, "Durability Of Steel Reinforced Concrete In Chloride Environments: An Overview," Constr. Build. Mater., Vol. 30, Pp. 125138, May (2012).

[5] Y. Zhao, H. Xu, And W. Jin, "Concrete Cracking Process Induced By Steel Corrosion- A Review," No. 2, Pp. 1-10. (2013).

[6] C. Cao, M. M. S. Cheung, And B. Y. B. Chan, "Modelling Of Interaction Between Corrosion-Induced Concrete Cover Crack And Steel Corrosion Rate," Corros. Sci., Vol. 69, No. 24, Pp. 97-109, (2013).

[7] C. Li, W. Lawanwisut, J. J. Zheng, And W. Kijawatworawet, "Crack Width Due To Corroded Bar In Reinforced Concrete Structures.Pdf,” Int. J. Mater. Struct. Reliab., Vol. 3 No 2, No. September, Pp. 87-94, (2005).

[8] Y. Zhao, J. Yu, And W. Jin, "Damage Analysis And Cracking Model Of Reinforced Concrete Structures With Rebar Corrosion," Corros. Sci., Vol. 53, No. 10, Pp. 3388-3397, Oct. (2011).

[9] Y. Zhao, J. Yu, Y. Wu, And W. Jin, "Critical Thickness Of Rust Layer At Inner And Out Surface Cracking Of Concrete Cover In Reinforced Concrete Structures," Corros. Sci., Vol. 59, Pp. 316-323, Jun. (2012).

[10] Y. Zhao, J. Yu, B. Hu, And W. Jin, "Crack Shape And Rust Distribution In Corrosion-Induced Cracking Concrete," Corros. Sci., Vol. 55, Pp. 385-393, Feb. (2012).

[11] C. Cao And M. M. S. Cheung, "Non-Uniform Rust Expansion For ChlorideInduced Pitting Corrosion In Rc Structures," Constr. Build. Mater., Vol. 51, Pp. 75-81, Jan. (2014).

[12] S. Muthulingam And B. N. Rao, "Non-Uniform Time-To-Corrosion Initiation In Steel Reinforced Concrete Under Chloride Environment," Corros. Sci., Vol. 82, Pp. 304-315, May (2014).

[13] Y. Zhao, B. Hu, J. Yu, And W. Jin, "Non-Uniform Distribution Of Rust Layer Around Steel Bar In Concrete," Corros. Sci., Vol. 53, No. 12, Pp. 4300-4308, Dec. (2011).

[14] Y. Zhao, A. Karimi, H. S. Wong, B. Hu, N. R. Buenfeld, And W. Jin, "Comparison Of Uniform And Non-Uniform Corrosion Induced Damage In Reinforced Concrete Based On A Gaussian Description Of The Corrosion Layer," Corros. Sci., Vol. 53, No. 9, Pp. 2803-2814, Sep.(2011).

[15] Y. Liu And R. Weyers, "Modeling Time To Corrosion Cracking In Chloride Contaminated Reinforced Concrete Structures," Aci Mater. Journals, Vol. 95, Pp. 675-681, (1998). 